\title{
Optimum signal wavelength for a distributed erbium-doped fiber amplifier
}

Rottwitt, Karsten; Povlsen, Jørn Hedegaard; Bjarklev, Anders Overgaard; Lumholt, Ole; Pedersen, Bo; Rasmussen, Thomas

Published in:

I E E E Photonics Technology Letters

Link to article, DOI:

$10.1109 / 68.145248$

Publication date:

1992

Document Version

Publisher's PDF, also known as Version of record

Link back to DTU Orbit

Citation (APA):

Rottwitt, K., Povlsen, J. H., Bjarklev, A. O., Lumholt, O., Pedersen, B., \& Rasmussen, T. (1992). Optimum signal wavelength for a distributed erbium-doped fiber amplifier. I E E E Photonics Technology Letters, 4(7), 714-717. https://doi.org/10.1109/68.145248

\section{General rights}

Copyright and moral rights for the publications made accessible in the public portal are retained by the authors and/or other copyright owners and it is a condition of accessing publications that users recognise and abide by the legal requirements associated with these rights.

- Users may download and print one copy of any publication from the public portal for the purpose of private study or research.

- You may not further distribute the material or use it for any profit-making activity or commercial gain

- You may freely distribute the URL identifying the publication in the public portal 
For the backward-pumping configuration, when the input signal is sufficiently high, the total pump-to-ASE conversion is small and the ASE noise-free model provides a fair approximation of the signal gain and conversion efficiency.

\section{REFERENCES}

[1] D. S. Forrester, A. M. Hill, R. A. Lobbett, R. Wyatt, and S. F. Carter, Electron. Lett., vol. 27, no. 22, p. 2051, 1991.

[2] R. I. Laming, J. E. Townsend, D. N. Payne, F. Meli, G. Grasso, and E. J. Tarbox, IEEE Photon. Technol. Lett., vol. 3, no. 3, p. 253, 1991.
[3] M. Suyama, I. Yokota, S. Watanabe, and H. Kuwahara, in Proc. Optical Amplifiers Appl., p. 174, paper ThE4, Opt. Soc. Amer., Washington, DC, 1991.

[4] A. A. Saleh, R. M. Jopson, J. D. Evankow, and J. Aspell, IEEE Photon. Technol. Lett., vol. 2, no. 10, p. 714, 1990.

[5] E. Desurvire, IEEE Photon. Technol. Lett., vol. 1, no. 10, p. 293, 1989.

[6] —- M. Zirngibl, H. M. Presby, and D. DiGiovanni, IEEE Photon. Technol. Lett., vol. 3, no. 2, p. 127, 1991.

[7] P. R. Morkel and R. I. Laming, Opt. Lett., vol. 14, no. 19, p. 1062, 1989.

[8] C. R. Giles and E. Desurvire, J. Lightwave Technol, vol. 9, no. 2, p. 271, 1991.

[9] E. Desurvire, C. R. Giles, and J. R. Simpson, J. Lightwave Technol., vol. 7 , no. 12 , p. 2095 , 1989.

\title{
Optimum Signal Wavelength for a Distributed Erbium-Doped Fiber Amplifier
}

\author{
Karsten Rottwitt, Jørn H. Povlsen, Anders Bjarklev, Ole Lumholt, Bo Pedersen, and \\ Thomas Rasmussen
}

\begin{abstract}
Theoretical analysis of a 100-km-long transparent germanosilicate distributed erbium-doped optical fiber has been carried out. It is shown that the optimum signal wavelength is $1.554 \mu \mathrm{m}$ both considering the noise performance and the necessary pump power for achieving unity gain when the distributed erbium-doped fibers are pumped at $1.48 \mu \mathrm{m}$.
\end{abstract}

\section{INTRODUCTION}

$\mathbf{I}_{\mathrm{r} e \mathrm{~s}}^{\mathrm{T}}$ has recently been shown that low signal excursion is required [1] in optical long-distance transmission systems; thus, distributed erbium doped optical fibers are applicable. Although previous work often has concentrated on the gain effective signal wavelength around $1.536 \mu \mathrm{m}$ [2], [3], other signal wavelengths are also usable for transmission through distributed erbium-doped fiber amplifiers (EDFA's). We have performed a detailed study of the distributed amplifier and identified the optimum signal wavelength, with respect to the necessary pump

Manuscript received February 7, 1992; revised April 28, 1992. This work was supported by the Danish Technical Research Council and by the National Agency of Industry and Trade, Denmark.

The authors are with the Center for Broadband Telecommunications, Electromagnetics Institute, Technical University of Denmark, DK-2800 Lyngby, Denmark.

IEEE Log Number 9201660. power for achieving transparency and the signal-to-noise ratio at the signal output end of the fiber.

The analysis is based on an accurate numerical model of a germanium-codoped distributed erbium-doped optical fiber [4]. Compared to the analytical model in [5], our numerical model includes a precise mode description of both the pump and signal power. Furthermore, it is not assumed that the distributed EDFA is operated in the small-signal regime. The minimum pump power and the noise figure are very sensitive to the accuracy of the wavelength dependency of the emission and absorption cross sections used in the model. The cross sections used here have been carefully determined from fluorescence and absorption measurements [4]. From this a 2-nm wavelength separation between each sample of the cross sections is achieved. Values within this spacing are found by interpolation. Throughout this letter the length of the fiber is $100 \mathrm{~km}$ with a numerical aperture of 0.2 and a $\mathrm{LP}_{11}$ cutoff wavelength of $1.22 \mu \mathrm{m}$, which results in a positive fiber dispersion of $3.2 \mathrm{ps} /(\mathrm{nm} \cdot \mathrm{km})$. The erbium dopant radius relative to the fiber core radius is 0.8 [6]. The distributed erbium-doped amplifier is pumped at 1.48 $\mu \mathrm{m}$. This is the only choice due to the high intrinsic loss at other pump bands. The intrinsic loss is $0.23 \mathrm{~dB} / \mathrm{km}$ at both the signal and pump wavelength. A bidirectional 
pumping scheme is used and the pump power values in the following are the total launched pump power.

\section{BASIC CONSIDERATIONS OF Distributed AMPLIFICATION}

For erbium-doped fiber amplifiers pumped at $1.48 \mu \mathrm{m}$ the threshold pump power is defined for an infinitesimal fiber piece at 0 -dB small-signal gain. The threshold pump power is an increasing function of the ratio $\sigma_{a} / \sigma_{e}$ between the absorption and emission cross sections at the signal wavelength. Also, the noise figure increases with the same ratio, indicating that the system performance may be improved by moving toward longer signal wavelengths where $\sigma_{a} / \sigma_{e}$ is lower. However, the necessary pump power for achieving transparency also depends on the magnitude of the emission cross section, which favors the signal wavelengths around the emission cross-section peak. In germanium-codoped EDFA's the emission spectrum shows a pronounced peak around $1.534 \mu \mathrm{m}$ and a weaker around $1.554 \mu \mathrm{m}$ [4]. In the following we analyze and compare distributed EDFA's used in long-distance communication systems, in order to identify the optimum signal wavelength. Thereby it will be shown that the benefits related to the lowered absorption to emission cross-section ratio at the $1.554-\mu \mathrm{m}$ signal wavelength are stronger than the drawbacks related with the weaker emission strength.

The signal-to-noise ratio at the signal input end of the fiber may be different at different signal wavelengths. This initial difference may occur at high signal powers when the optical Kerr effect in the fiber is used to form solitary pulses [7], or when the signal power level is fixed. First we consider an equal signal-to-noise ratio at the signal input end of the fiber equivalent to a fixed input mean signal photon number. The signal-to-noise ratio at the output end of the fiber is $(S / N)_{\text {out }}=\left\langle n_{0}\right\rangle / F$ for a coherent source [8], where $\left\langle n_{0}\right\rangle$ is the mean number of signal photons emitted from the source and $F$ is the noise figure of the fiber. Comparing the two signal wavelengths $\lambda_{1}$ and $\lambda_{2}$, the signal-to-noise ratio, valid at the signal output end of the fiber, is related through $(S / N)_{\lambda_{1}}=F_{2} / F_{1} \cdot(S / N)_{\lambda_{2}}$ $F_{1}$ and $F_{2}$ are the noise figures calculated at $\lambda_{1}$ and $\lambda_{2}$ with the two signal powers $P_{1}$ and $P_{2}$, respectively. Second, if the initial signal-to-noise ratio is different, the signal-to-noise ratio at the signal input end is $(S / N)_{\lambda_{1}}=$ $\left(\left\langle n_{0}\right\rangle_{\lambda_{1}} /\left\langle n_{0}\right\rangle_{\lambda_{2}}\right) \cdot(S / N)_{\lambda_{2}}$, where $\left\langle n_{0}\right\rangle_{\lambda_{1}}$ and $\left\langle n_{0}\right\rangle_{\lambda_{2}}$ are the mean numbers of emitted signal photons at $\lambda_{1}$ and $\lambda_{2}$, respectively. At the signal output end of the fiber the signal-to-noise ratio is given by $(S / N)_{\lambda_{1}}=$ $\left(\left\langle n_{0}\right\rangle_{\lambda_{1}} /\left\langle n_{0}\right\rangle_{\lambda_{2}}\right) \cdot F_{2} / F_{1} \cdot(S / N)_{\lambda_{2}}$. As the initial difference in the signal-to-noise ratio at the input end of the fiber $\left(\left\langle n_{0}\right\rangle_{\lambda_{1}} /\left\langle n_{0}\right\rangle_{\lambda_{2}}\right.$ ) typically is less than $0.2 \mathrm{~dB}$, the following discussion will be focussed on the factor $F_{2} / F_{1}$.

\section{OPtimum Signal WAVElength}

Fig. 1 displays the pump power necessary to obtain transparency and the corresponding noise figure as a function of the signal wavelength. The mean signal input

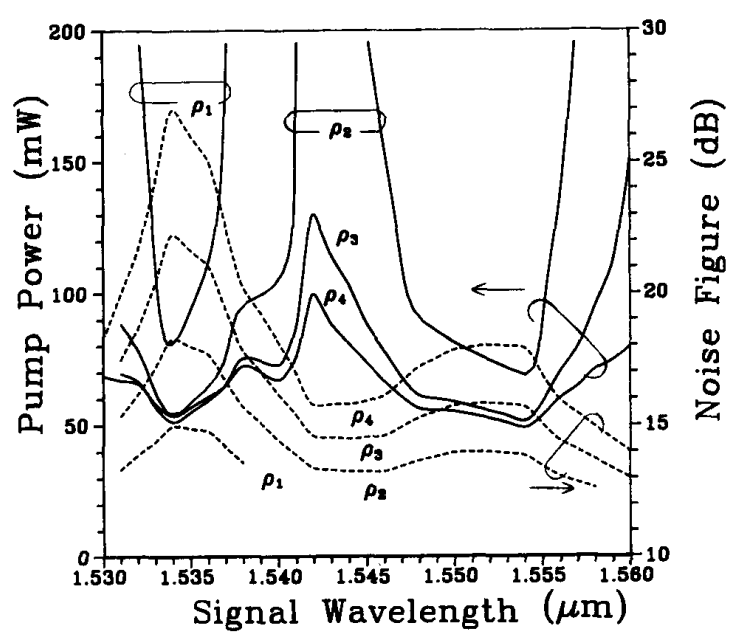

Fig. 1. Pump power necessary to obtain transparency and noise figure versus signal wavelength. Both functions are shown for four different values of the erbium dopant concentration, varied equidistantly between $\rho_{1}=5.0 \cdot 10^{20} \mathrm{~m}^{-3}$ and $\rho_{4}=1.5 \cdot 10^{21} \mathrm{~m}^{-3}$.

power is $0.1 \mathrm{~mW}$, and the curves are shown for different levels of erbium concentrations. From the figure it is seen that both the necessary pump power and the noise figure are strongly dependent on the signal wavelength and the erbium concentration. It is observed that the necessary pump power for transparency has minima at the two signal wavelengths of 1.534 and $1.554 \mu \mathrm{m}$. These two wavelengths coincide with the wavelengths where the emission and absorption spectra have peaks. However, the noise figure also has maxima at these two signal wavelengths, and it is not clear whether an optimum signal wavelength exists when the noise figure is considered. Thus, comparisons of the noise figure must be made on the basis of an equal pump power level. Fig. 2 shows the noise figure as a function of the signal wavelength. Curves are shown for different levels of pump powers and for each point in the figure the erbium concentration is adjusted until transparency is obtained. From this figure it is seen that the optimum signal wavelength with respect to the noise figure is $1.554 \mu \mathrm{m}$ for all the pump power levels shown. From Fig. 2 it is further seen that the curves have a local minimum at $1.534 \mu \mathrm{m}$, but around this signal wavelength the noise figure is very wavelength dependent. Around $1.554 \mu \mathrm{m}$ the noise figure is less sensitive to variations in the signal wavelength. The two signal wavelengths, 1.534 and $1.554 \mu \mathrm{m}$, are compared in further detail in the inset of Fig. 2. For the $1.534-\mu \mathrm{m}$ signal wavelength the lowest necessary pump power for transparency is $50.9 \mathrm{~mW}$, which results in a noise figure of 21.5 dB. The lowest pump power for the $1.554-\mu \mathrm{m}$ signal wavelength is $48.6 \mathrm{~mW}$, resulting in a noise figure of 17.8 dB. Considering next a fixed pump power consumption of $100 \mathrm{~mW}$, a noise figure of $14.4 \mathrm{~dB}$ is achieved at the $1.534-\mu \mathrm{m}$ signal wavelength, whereas the $1.554-\mu \mathrm{m}$ signal wavelength results in a noise figure of $13.1 \mathrm{~dB}$, which is an improvement of $1.3 \mathrm{~dB}$. From the figures it is therefore 


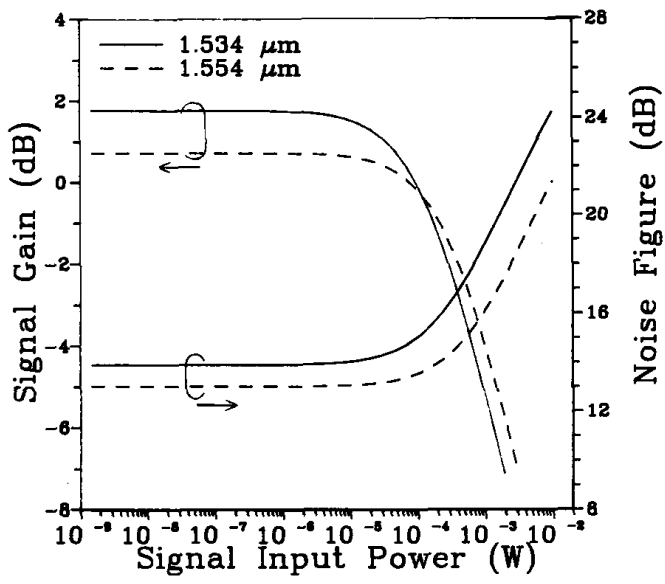

Fig. 2. Signal gain and noise figure versus the signal input power for two signal wavelengths, $1.534 \mu \mathrm{m}$ (solid) and $1.554 \mu \mathrm{m}$ (dashed). Both are calculated with $0-\mathrm{dB}$ gain for pump power of $80 \mathrm{~mW}$ at $0.1-\mathrm{mW}$ signal power.

concluded that the optimum signal wavelength is 1.554 $\mu \mathrm{m}$.

The conclusions above are based on calculations for a 100-km-long distributed EDFA having an erbium dopant radius 0.8 times the fiber core radius. However, under the assumption that the cross-section spectra are independent on the fraction between the erbium dopant radius and the fiber core radius, the above conclusion is valid at other values of this fraction. Furthermore, it is expected that the optimum signal wavelength is the same at other fiber lengths[5]. Calculations for a fiber with the erbium dopant radius changed to 0.02 times the fiber core radius result in the same optimum signal wavelength. However, the minimum pump power at $1.554 \mu \mathrm{m}$ is reduced to $35.0 \mathrm{~mW}$ and the noise figure at $100-\mathrm{mW}$ pump power is $12.8 \mathrm{~dB}$. Changing the fiber length to $50 \mathrm{~km}$ also results in the same optimum signal wavelength. In this situation the minimum pump power for transparency is $11.5-\mathrm{mW}$. In nonlinear systems the signal power excursions should remain below $10 \mathrm{~dB}$ in order not to dominate the amplitude noise and the timing jitter [1]. Our calculations shows that the signal power excursions increases with decreasing pump power. More important, the signal wavelength where the signal power excursions are lowest are coinciding with the optimum signal wavelength, $1.554 \mu \mathrm{m}$. For a pump power of $50 \mathrm{~mW}$ the signal power excursions was below 4 dB.

To calculate the improvement $\left(F_{2} / F_{1}\right)$, it is as mentioned earlier essential to evaluate the signal-to-noise ratio at the signal output end of the distributed EDFA. In the previous analysis a fixed signal power of $0.1 \mathrm{~mW}$ was used at the two signal wavelengths. At this signal power the distributed EDFA is operated in the large-signal region as the gain decreases with increasing signal power according to Fig. 3. A comparison between different signal wavelengths may be performed on the basis of an equal signal-to-noise ratio at the signal input end of the fiber or

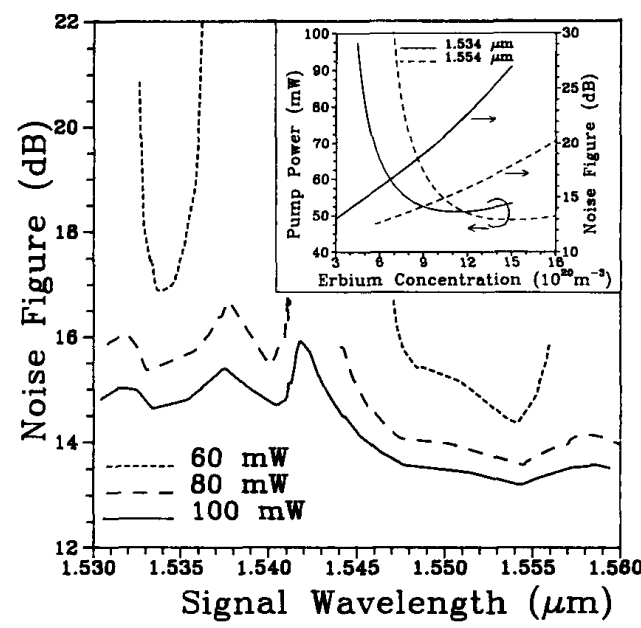

Fig. 3. Noise figure versus signal wavelength for three different total pump powers: 60,80 , and $100 \mathrm{~mW}$. The inset shows the necessary pump power for transparency and the noise figure versus the erbium dopant concentration for signal wavelengths of $1.534 \mu \mathrm{m}$ (solid) and $1.554 \mu \mathrm{m}$ (dashed).

the same solitary pulse. Thus, the signal power launched to the distributed EDFA has to be adjusted, and hence the noise figure will change according to Fig. 3. However, calculations show that the noise figures change less than $1 \%$ when the signal power is adjusted either to give the same solitary pulse or an equal signal-to-noise ratio at the signal input end of the fiber at the two signal wavelengths, 1.534 and $1.554 \mu \mathrm{m}$, considered in this communication.

\section{CONCLUSION}

In a $100-\mathrm{km}$-long distributed erbium-doped fiber amplifier, different signal wavelengths, in the region between 1.530 and $1.560 \mu \mathrm{m}$, are compared with respect to the necessary pump power for achieving transparency and noise performance. It is shown that the $1.554-\mu \mathrm{m}$ signal wavelength is the optimum choice. Further comparisons of the 1.534- and $1.554-\mu \mathrm{m}$ signal wavelengths show that the necessary pump power for achieving transparency is reduced by $2.3 \mathrm{~mW}$ when the latter signal wavelength is used. Working where the pump power consumption is minimized results in an improvement of $3.7 \mathrm{~dB}$ in the noise figure. Furthermore, an improvement in the signalto-noise ratio at the signal output end of the fiber of 1.3 $\mathrm{dB}$ is achieved when the pump-power consumption is fixed at $100 \mathrm{~mW}$ for both signal wavelengths.

\section{ACKNOWLEDGMENT}

The authors would like to thank Dr. E. Nicolaisen for inspiring discussions.

\section{REFERENCES}

[1] J. P. Gordon and L. F. Mollenauer, "Effects of fiber nonlinearities and amplifier spacing on ultra-long distance transmission," $J$. Lightwave Technol., vol. 9, no. 2, pp. 170-173, Feb. 1991.

[2] G. R. Walker, D. M. Spirit, D. L. Williams, and S. T. Davey, "Noise performance of distributed fibre amplifiers," Electron. Lett., vol. 27 , no. 15 , pp. $1390-1391$, July 1991.

[3] M. Yamada et al., "Noise characteristics of $\mathrm{Er}^{3+}$-doped fiber 
amplifiers pumped by 0.98 and $1.48 \mu \mathrm{m}$ laser diodes," IEEE Photon. Technol. Lett., vol. 2, no. 3, pp. 205-207, Mar. 1990.

[4] B. Pedersen, A. Blarklev, J. H. Povlsen, K. Dybdal, and C. C. Larsen, "The design of erbium-doped fiber amplifiers," J. Lightwave Technol., vol. 9, no. 9, pp. 1105-1112, Sept. 1991.

[5] E. Desurvire, "Analysis of distributed erbium-doped fiber amplifiers with fiber background loss," IEEE Photon. Technol. Lett., vol. 3 , no. 7, pp. 625-628, July 1991 .

[6] K. Rottwitt, A. Bjarklev, O. Lumholt, J. H. Povlsen, and T. Ras- mussen, "Design of a long distance distributed erbium doped fibre amplifier," Electron. Lett., vol. 28, no. 3, pp. 287-288, Jan. 1992.

[7] L. F. Mollenauer, S. G. Evangiledes, Jr., and H. A. Haus, "Longdistance soliton propagation using lumped amplifiers and dispersion shifted fiber," J. Lightwave Technol., vol. 9, no. 2, pp. 194-197, Feb. 1991.

[8] E. Desurvire, "Spectral noise figure of $\mathrm{Er}^{3+}$-doped fiber amplifiers," IEEE Photon. Technol. Lett., vol. 2, no. 3, pp. 208-210, Mar. 1990.

\title{
$1111 \mathrm{~km}$, Two-Channel IM-DD Transmission Experiment at $2.5 \mathrm{~Gb} / \mathrm{s}$ Through 21 In-Line Erbium-Doped Fiber Amplifiers
}

\author{
P. M. Gabla, J. O. Frorud, E. Leclerc, S. Gauchard, and V. Havard
}

\begin{abstract}
Two-channel transmission is demonstrated in a 2.5 $\mathrm{Gb} / \mathrm{s}$ intensity-modulated direct-detection system over a distance of $1111 \mathrm{~km}$, using 21 in-line erbium-doped fiber amplifiers. The two channels incur virtually no penalty when they are transmitted simultaneously. Owing to the use of gain filtering in the amplifiers instead of discrete in-line optical filters, the overall bandwidth of the link is about $15 \mathrm{~nm}$, for a sensitivity penalty smaller than $1 \mathrm{~dB}$ on one single transmitted channel.
\end{abstract}

\section{INTRODUCTION}

$\mathrm{E}$ RBIUM-DOPED fiber amplifiers (EDFA) have shown great potential as postamplifiers, preamplifiers, and in-line repeaters in future optical communication systems. Impressive results have been obtained in very long haul digital transmission experiments [1]-[7]. They have proven the feasibility of $2.5 \mathrm{Gbit} / \mathrm{s}$ single channel optically amplified links on a distance longer than $4000 \mathrm{~km}$ in a straight-line experiment [4], and longer than $21000 \mathrm{~km}$ in a recirculating loop experiment [7].

After such links are installed, the perpetual thrust for higher capacities will foster the emergence of upgrade solutions for existing links. The dream of an optical pipeline is persistent and one would like to upgrade the system just by changing the terminals. Indeed optical amplification is essentially transparent to the signal characteristics but an optically amplified system is not. The

Manuscript received January 20, 1992

P. M. Gabla, E. Leclerc, S. Gauchard, and V. Havard are with Alcatel CIT, F-91625 La Ville du Bois Cedex, France.

J. O. Frorud is with Alcatel Telecom Norway, N-0511 Oslo 5, Norway. IEEE Log Number 9201240. maximum distance that can be bridged depends of course on the bit rate and modulation format, but also on the number of wavelength-division multiplexed channels. It is therefore interesting to look at the alternatives for upgrade: single channel bit rate increase [7] or multichannel wavelength-division multiplexing (WDM) with a fixed bit rate [8].

The limitations in a very long distance nonregenerated system come from optical amplifier noise and saturation power [9], and from nonlinear effects in the transmission fiber [10]. A higher bit rate leads to a degradation of the signal-to-noise ratio because of the bandwidth increase, and to a sharper influence of nonlinear effects-essentially the optical Kerr effect-because of the shorter bit time slot. Therefore wavelength multiplexing of several channels at a lower bit rate offer an interesting alternative, but in this case new limitations arise from the available total output power of each amplifier and from the possibility of four-wave mixing (FWM), another consequence of fiber nonlinearity [11].

In this letter, we present a two-channel transmission experiment at $2.5 \mathrm{~Gb} / \mathrm{s}$ IM-DD, bridging a distance of $1111 \mathrm{~km}$ through 21 in-line EDFA's and operating with almost no penalty on either channel.

\section{EXPERIMENT SETUP}

The setup is shown in Fig. 1. Each of the two transmitters consists of a DFB laser and a $\mathrm{LiNbO}_{3}$ Mach-Zehnder external modulator (MOD). The two DFB lasers operate at the wavelengths of 1550.5 (channel 1) and $1553.6 \mathrm{~nm}$ (channel 2). The modulators are each driven by a 2.488 